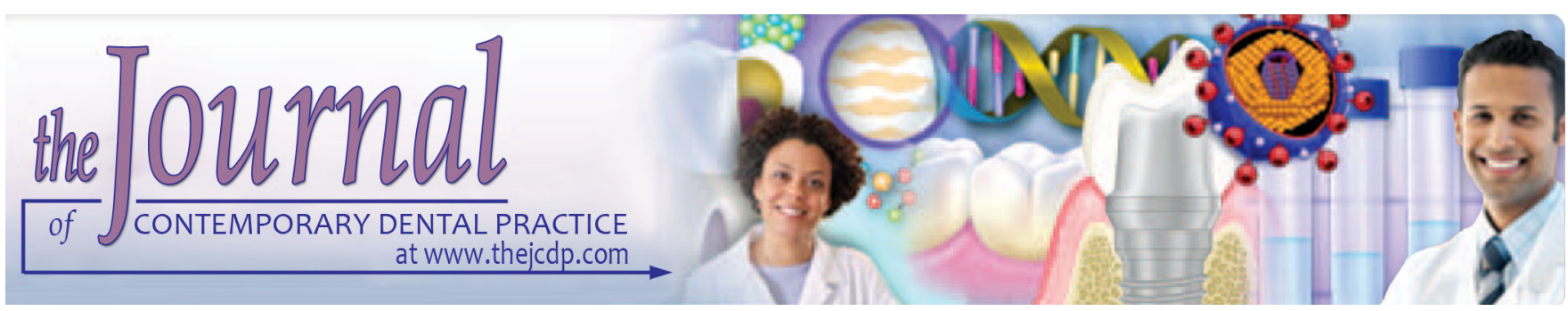

\title{
Quality of Life related to Eruption Hematoma in a Twenty Months Old Infant
}

\author{
${ }^{1}$ Andréa Laudares Marques, ${ }^{2}$ Nashalie Andrade de Alencar, ${ }^{3}$ Lucianne Cople Maia, ${ }^{4}$ Andréa Gonçalves Antonio
}

\section{ABSTRACT}

Aim: This paper describes a case of an eruption hematoma in a 20-month-old boy and the impact of this hematoma on the quality of life (QoL) related to oral health of this infant and his family.

Background: Eruption hematoma is a soft benign cyst that contains blood and overlie a tooth that are about to erupt. Oral health conditions can affect the QoL and bring psychological impacts.

Case report: The proposed treatment was based on oral hygiene instruction, normal diet and massage on the lesion area. A weekly follow-up visits up to the spontaneous regression at the 6 weeks of the lesion was conducted. The impact on QoL was assessed though the Brazilian version of the early childhood Oral Health Impact Scale (B-ECOHIS) questionnaire before and after 2 months of the hematoma regression.

Conclusion: The presence of eruption hematoma impacted, physically and emotionally, the QoL related to oral health of the child and his family, and this impact decreased when the eruption hematoma disappeared.

Clinical significance: It is important the knowledge of the dentists about eruption cyst/hematoma to make the correct decisions to improve the QoL of their patients and families.

Keywords: B-ECOHIS, Case report, Eruption hematoma, Infant, Quality of life.

How to cite this article: Marques AL, de Alencar NA, Maia LC, Antonio AG. Quality of Life related to Eruption Hematoma in a Twenty Months Old Infant. J Contemp Dent Pract 2015;16(9): 763-767.

\section{Source of support: Nil}

Conflict of interest: None

\footnotetext{
${ }^{1-4}$ Department of Pediatric Dentistry and Orthodontics, School of Dentistry, Universidade Federal do Rio de Janeiro, RJ, Brazil

Corresponding Author: Andréa Gonçalves Antonio, Adjunct Professor, Department of Pediatric Dentistry and Orthodontics Rua Professor Coutinho Fróis, 500/301, Barra da Tijuca Rio de Janeiro, CEP: 22620-360, Brazil, Phone: 005521 2562.2098 e-mail: andreagantonio@yahoo.com.br
}

\section{INTRODUCTION}

Eruption cyst is a soft tissue benign cyst accompanying with an erupting primary or permanent teeth, which appears shortly before the involved tooth emerges in the oral cavity. ${ }^{1}$ When the tumefaction around the tooth crown contains blood, the eruption cyst can end-up turning the gums a blue or gray color. In this case, the cyst is called eruption hematoma. ${ }^{2}$ In the past, they were classified as a dentigerous cyst. However, many authors consider eruption cyst a lesion dissimilar to dentigerous cyst, since the last one occurs within the soft tissues overlying a tooth in eruption. ${ }^{3,4}$

It normally occurs in the first decade of life, in single or multiple, unilateral or bilateral form, in the maxillary or mandibular arch, ${ }^{5}$ but it appears to be more prevalent in the maxillary arch. ${ }^{1}$ Gender predilection of eruption cyst is controversial. Some authors reported a male predilection in a rate of $2: 1^{1,4}$ whereas others found no gender differences ${ }^{6}$ or a female predilection. ${ }^{5}$

Oral health conditions are one of the most important factors that can affect the people's quality of life. Bad oral conditions can bring psychological impacts as well as hamper physical activities, such as speaking, smiling, kissing, eating and tasting. ${ }^{3}$ The early childhood oral Health Impact Scale (ECOHIS) is a measure of children's oral health-related quality of life (OHRQoL) designed to assess the impact of oral conditions on the quality of life among preschool children. This tool is composed by 13 questions, which assess both the child and the family impacts. ${ }^{7}$ Many oral disorders have been related to the impact on the children' OHRQoL, such as dental caries, ${ }^{8,9}$ bruxism $^{10,11}$ and dental trauma. ${ }^{9,12-14}$ However, studies or case reports that demonstrated the influence of eruption hematoma on the child's QoL related to oral health were not found on the PubMed database during a search performed in September 2014, using keywords: 
eruption hematoma, eruption cyst, QoL and child and/ or infant. Thus, the aim of this study was to report the management of an eruption hematoma in an infant of 20-month-old and its impact on his quality of life related to oral health.

\section{CASE DESCRIPTION}

A 20-month-old male infant was brought by her mother to the pediatric dental clinic of a public university in Rio de Janeiro, Brazil. The mother's chief complaint was the presence of 'a bubble in the baby's mouth'. According to her, the lesion had appeared 2 months before the first appointment in the mentioned dental clinic. Moreover, the child had difficulty of chewing and the mother also reported that it has been worsening day after day, mainly because the lesion had increased in size since then.

The baby was born by normal childbirth, without intercurrences. The patient's medical history revealed no specific problems and he was not under medication. As described by her mother, the infant was exclusively breastfed up to 2 months old and he no longer uses a baby bottle because it makes him retching. His diet was solid and pasty but after the eruption hematoma the infant had difficult of eating solid food. The mother did not report any dental trauma, the baby uses a pacifier and has the habit of biting objects.

Extraoral examination did not reveal abnormalities. The intraoral examination revealed eruption of the central and lateral maxillary incisors, the central and lateral mandibular incisors and also the mandibular canines. There was an anterior open bite and no clinical sign of caries. It was observed a fluctuating swelling with about $15 \mathrm{~mm}$ of width; containing liquid with translucent bluish appearance at the gingival mucosa in the area of the no erupted first primary right mandibular molar (Fig. 1). These clinical signs suggested it was an eruption hematoma. The radiographic examination confirmed the presence of the first primary right mandibular molar and its eruption was associated with the present lesion (Fig. 2).

The proposed treatment for the patient included oral hygiene instruction for mother, normal diet and massage on the area of the lesion several times a day with the help of a teething ring. The patient was schedule weekly up to the 6 th week, when there was spontaneous regression of the hematoma (Fig. 3) and the beginning of the eruption of the associated tooth (Fig. 4).
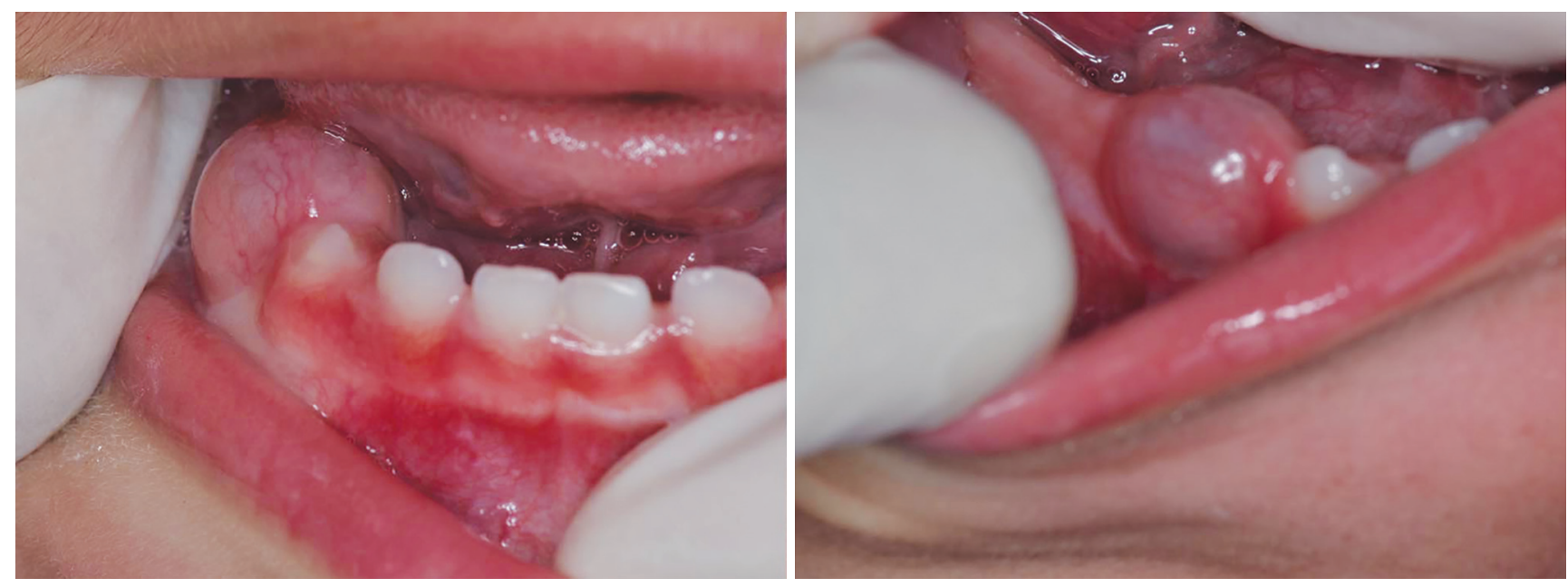

Fig. 1: Erupted hematoma at the first primary right mandibular molar region
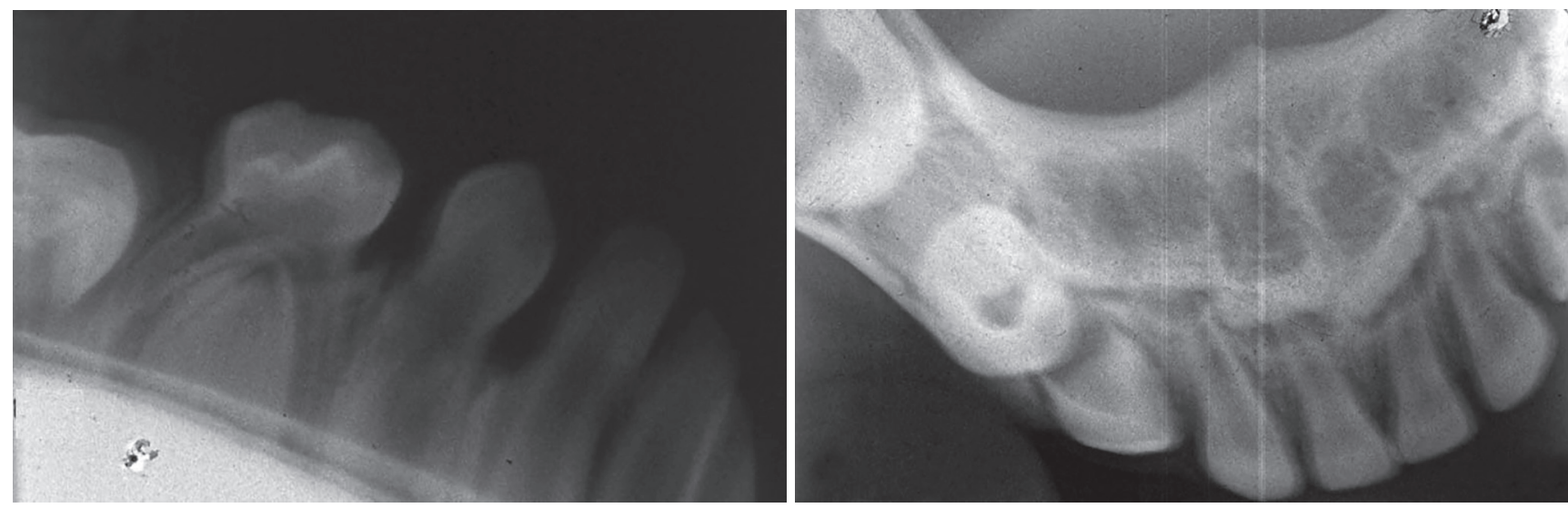

Fig. 2: The radiographs that showed the presence of the first primary right mandibular tooth 


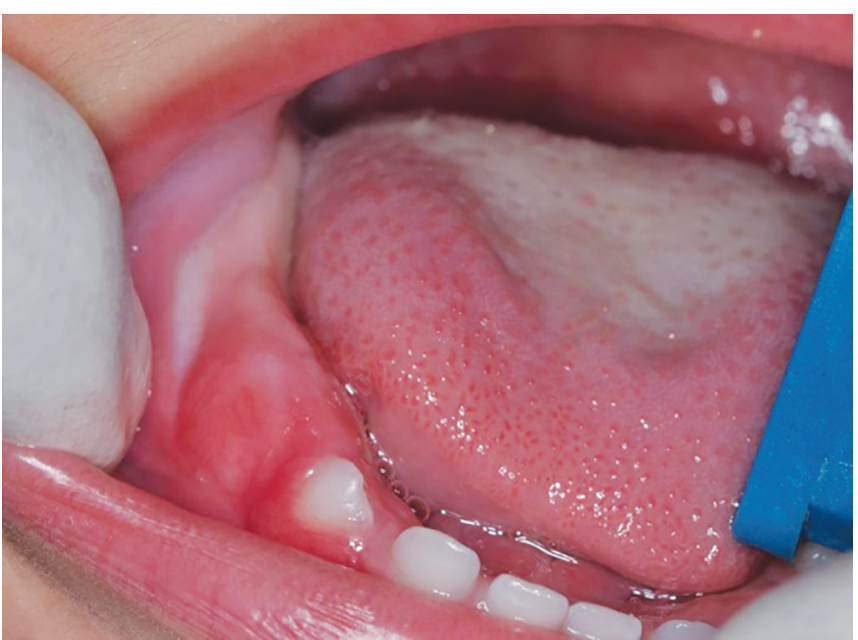

Fig. 3: The regression of the erupted hematoma

The Brazilian version of the Early Childhood Oral Health Impact Scale (B-ECOHIS) was applied in two different moments to measure the QoL related to oral health: (1) at the first appointment and (2) two months after the eruption hematoma remission. It has 13 questions directed to the parents that evaluate the child impact on QoL related to oral heath (nine questions) and the family impact on QoL related to oral health (four questions) (Table 1). In addition, four general questions for a more accurate evaluation were applied. The total score of the B-ECOHIS was obtained after a simple sum of the answers' code. The child impact on QoL score ranges from 0 to 36, the family impact ranges from 0 to 16 . Thus, $\mathrm{B}$-ECOHIS questionnaire ranges from 0 to 52 points. The general questions scores ranges from 4 to 20. Finally, the total score of all questions can range from 4 to 72 .

At the first moment (T1), the mother related that his child had difficulty eating solid foods and he was irritable or frustrated because of the eruption hematoma. She considers the oral health of her child reasonable compared with other children with the same age, as well as his general state of health. The total score at this first moment was 30 . At the second moment (T2) the mother was very grateful and has not any complaint about the oral health of her child. Her only complaint was about the general health of the child, who was not sleeping well. The tooth had erupted and the child was eating normally. The total score number at the final moment was 23 (Table 1).

\section{DISCUSSION}

The prevalence of eruption cyst or hematoma was not studied thoroughly. ${ }^{15}$ Most of the cases of eruption hematoma were at the first decade of life, when the primary dentition and many of the permanent teeth normally erupt. ${ }^{4}$ The etiology of eruption hematoma is still unknown. Early caries, trauma, infection and the

Table 1: Total score of B-ECOHIS at the two different moments (M1: at the first appointment, M2: 2 months after the eruption hematoma remission

\begin{tabular}{lll}
\hline Domains & M1 & M2 \\
\hline Child with pain in the teeth, mouth or jaw & 1 & 1 \\
Child with difficulty in drinking hot or cold beverages & 1 & 1 \\
Child with difficulty in eating certain foods & 4 & 1 \\
Child with difficulty to pronounce some words & 1 & 1 \\
Child missed the nursery, kindergarten or school & 1 & 1 \\
Child had difficulty sleeping & 1 & 1 \\
Child became angry & 4 & 1 \\
Child avoided smiling & 1 & 1 \\
Child avoided talking & 1 & 1 \\
Caretaker became upset & 4 & 1 \\
Caretaker felt guilt & 1 & 1 \\
Caretaker missed work & 1 & 1 \\
Caretaker felt the financial impact on the family & 1 & 1 \\
Oral health status of the child & 3 & 2 \\
General health of the child & 3 & 3 \\
Wellbeing of caretaker was affected & 1 & 2 \\
Wellbeing of child was affected & 1 & 3 \\
\hline Total score of B-ECOHIS & 30 & 23 \\
\hline
\end{tabular}

Note: Responses are coded: $0=$ never; $1=$ hardly ever; $2=$ occasionally; 3 = often; 4 = very often; $5=$ don't know. Total scores were calculated as a simple sum of the response codes

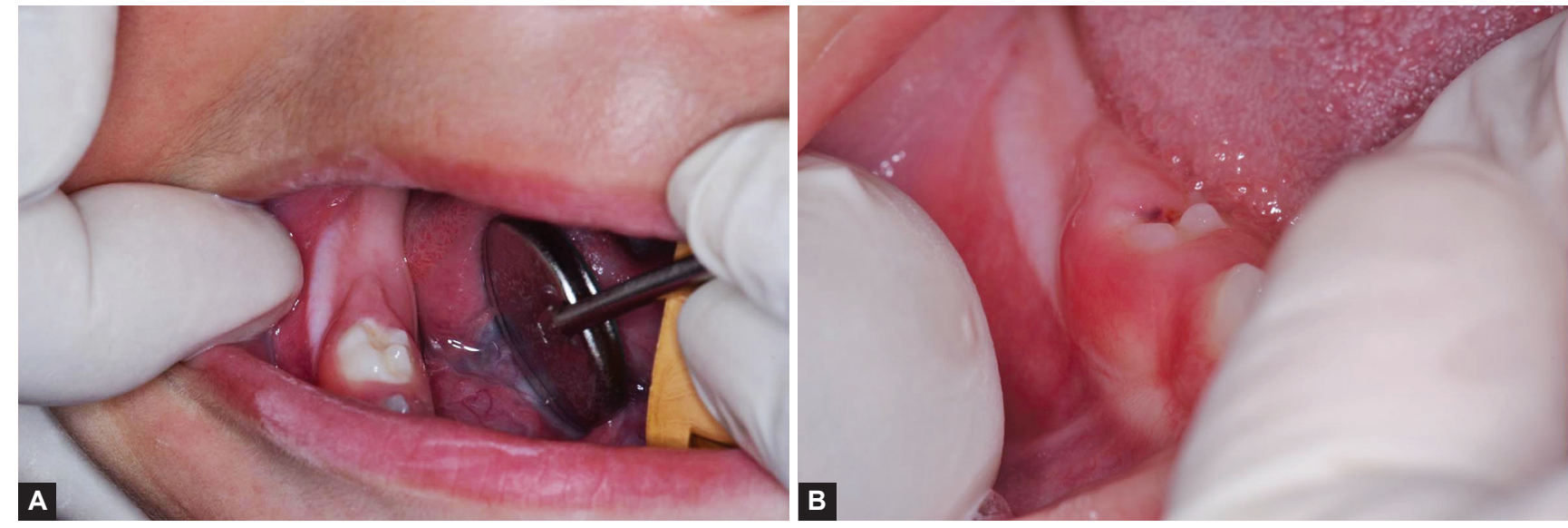

Figs 4A and B: (A) The beginning of the eruption of the tooth associated to the hematoma and (B) First primary right mandibular tooth in the arch 
deficient space for eruption were proposed by ${ }^{6}$ as possible etiological factors. $\mathrm{O}^{\prime} \mathrm{Hara}^{16}$ described an association between cyclosporine administration and the formation of eruption cyst/hematoma in golden retriever pups. In the present case, the patient was not taken medicines. Also, no dental trauma and no infection were reported. On the other hand, an open bite was detected, which could trigger strength of the arch and consequently cause a space problem for tooth eruption. However, even with this malocclusion, there was sufficient space for the first right mandibular tooth in the arch. Thus, the etiology of the present case was not discovered, which corroborated with the literature. ${ }^{15,17,18}$

Radiography is essential for diagnosis of the some odontogenic cysts, but eruption cyst/hematoma cannot be detected with this examination..$^{19}$ Even so, Woldenberg ${ }^{20}$ stated that radiograph is highly recommended for evaluation of the involved tooth morphology or its surrounding jaw bone. In the present case, the radiographic examination was carried out and concurred to the diagnose of the eruption hematoma.

The most of eruption cyst has spontaneous regression and ordinarily it is not necessary any treatment. ${ }^{21}$ In the present case, the eruption hematoma had a spontaneous regression after 6 weeks of monitoring and the associated tooth erupted without complications. It is recommended to massage the gums, which can relieve discomfort and be soothing. ${ }^{2}$ According to the mother, the baby felt relief of discomfort after the massages had been performed. Also, when the cyst is hurt, bleed, infected, or when esthetic problems arise, the surgical intervention as treatment could be considered. ${ }^{1}$ In the present case, this kind of treatment was not necessary, because although the bleed, no infection and esthetic problems were observed. Thus, the authors chose to the conservative procedure, such as normal feeding with solid foods and massage on the lesion, which was sufficient.

In recent years, oral health related to QoL measures have been designed for the child population. ${ }^{7}$ The B-ECOHIS questionnaire measures the impact of oral problems on QoL among preschool children of about 0 to 5 years of age. ${ }^{7}$ At first application of B-ECOHIS (T1) the negatives points related by the mother were child with difficulty to eat certain foods, child became angry due to oral problems, and caretaker became upset due to child's oral problems, the oral health status of the child and the general health of the child. The difficulty in chewing can be related with the height of the eruption hematoma that was interfering with occlusion and consequently the infant could not eat certain foods, affecting the well being of child and his family.
At second application of B-ECOHIS (T2), the scores about the wellbeing of caretaker and the infant were higher than in the first moment (T1). According to the mother, all the problems reported at $\mathrm{T} 2$ were about the general health of the child, mainly because he was not sleeping during all night, which affected her sleep too. She added that the hematoma in oral cavity also influenced the general health of the infant at this first moment. As the B-ECOHIS is a questionnaire of general health, oral health is not separate and so, the difference of results at $\mathrm{T} 1$ and T2 were not so significant since the second time the mother complained more about the general health.

We can assert through the B-ECOHIS that the quality of the child's life related to oral health improved after the regression of the eruption hematoma and that this cyst affects the child and his family physically and emotionally.

\section{CONCLUSION}

It is very common that the size and color of an eruption hematoma alarmed the responsible. In this report, the mother got very scared and worried. She was instructed by a dentist to seek treatment with a pediatric dentist. Thus, it is very important the knowledge of the dentists in detect the signs and symptoms of the eruption cyst/ hematoma to make a correct diagnosis and treatment. Dentists need to reassure their patients' responsible to reduce their anxiety to improve the QoL related to oral health of their patients and families.

\section{CLINICAL SIGNIFICANCE}

It is important the knowledge of the dentists about eruption cyst/ hematoma to make the correct decisions to improve the QoL of their patients and families.

\section{ACKNOWLEDGMENT}

The authors acknowledge the scholarships and financial support from Fundação de Amparo à Pesquisa do Estado do Rio de Janeiro (FAPERJ).

\section{REFERENCES}

1. Anderson RA. Eruption cysts: a retrograde study. Journal of Dentistry for Children 1990;57(2):124-127.

2. Coser RM, Flório FM, Melo BP, Quaglio JM. Características clínicas do cisto de erupção. Revista Gaúcha de Odontologia Brasil 2004;52(3):180-183.

3. World Health Organization. The world oral health report 2003: Continuous improvement of oral health in the 21st century. The approach of the WHO Global Oral Health Programme. Geneva: WHO; 2003.

4. Bodner L, Goldstein J, Sarnat H. Eruption cysts: a clinical report of 24 new cases. J Clin Pedia Dentist 2004;28(2): 183-186. 
5. Seward MH. Eruption cyst: an analysis of its clinical features. J Oral Surg 1973;31(1):31-35.

6. Aguiló L, Cibrián R, Bagán JV, Gandía JL. Eruption cysts: retrospective clinical study of 36 cases. American Society of Dentistry for Children. J Dentist Children 1998;65(2):102-106.

7. Scarpelli AC, Oliveira BH, Tesch FC, Leão AT, Pordeus IA, Paiva SM. Psychometric properties of the Brazilian version of the Early Childhood Oral Health Impact Scale (B-ECOHIS). BMC Oral Health 2011;13:11-19.

8. Low W, Tan S, Schwartz S. The effect of severe caries on the quality of life in young children. Pediat Dentist 1999; 21(6): 325-326.

9. AbantoJ,CarvalhoTS,MendesFM,Wanderley MT, BoneckerM, Raggio DP. Impact of oral diseases and disorders on oral health-related quality of life of preschool children. Community Dentist Oral Epidemiol 2011;39(2):105-114.

10. Castelo PM, Barbosa TS, Gavião MB. Quality of life evaluation of children with sleep bruxism. BMC Oral Health 2010;14: $10-16$.

11. Barbosa TS, Leme MS, Castelo PM, Gavião MBD. Evaluation oral health-related quality of life measure for children and preadolescents with temporomandibular disorder. Health and Quality of Life Outcomes 2011;12:9-32.

12. Cortes MI, Marcenes W, Sheiham A. Impact of traumatic injuries to the permanent teeth on the oral health-related quality of life in 12 to 14-year-old children. Community Dentist Oral Epidemiol 2002;30(3):193-198.
13. Berger TD, Kenny DJ, Casas MJ, Barrett EJ, Lawrence HP. Effects of severe dentoalveolar trauma on the quality-of-life of children and parents. Dent Traumatol 2009;25(5):462-469.

14. Bendo CB, Paiva SM, Torres CS, Oliveira AC, Goursand D, Pordeus IA, Vale MP. Association between treated/untreated traumatic dental injuries and impact on quality of life of Brazilian schoolchildren. Health and Quality of Life Outcomes 2010;4:8-114.

15. Nagaveni NB, Umashankara KV, Radhika NB, Maj Satisha TS. Eruption cyst: a literature review and four case reports. Ind J Dent Res 2011;22(1):148-151.

16. O'Hara AJ, Collins T, Howell JM. Gingival eruption cysts induced by cyclosporine administration to neonatal dogs. J Clin Periodontol 2002;29(6):507-513.

17. Preeti D, Gulsheen KK, Sanjay C, Shweta A. Eruption Cysts: A serie of two cases. Dent Res J (Isfahan) 2012;9(5):647-650.

18. Figueiredo NR, Meena M, Dinkar AD, Khorate M, Satoskar SK. Eruption cyst: a case report. Annals and Essences of Dentist 2013;5(4):9-12.

19. Navas RM, Mendoza MG, Leonardo MR, Silva RA, Herrera HW, Herrera HP. Congenital eruption cyst: a case report. Brazilian Dent J 2010;21(3):259-262.

20. Woldenberg Y, Goldstein J, Bodner L. Eruption cyst in the adult: a case report. Int J Oral Maxillofac Surg 2004;33(8):804-805.

21. Neville BW, Damm DD, Allen CM, Bouquot JE. Oral and maxillofacial pathology. 3rd ed. Pennsylvania: Sauders, An imprint of Elsevier; 2009. p. 682-683. 